Article

\title{
Long-Term Water Storage Changes of Lake Volta from GRACE and Satellite Altimetry and Connections with Regional Climate
}

\author{
Shengnan $\mathrm{Ni}^{1,2, *} \mathbb{C}$, Jianli Chen ${ }^{3}$, Clark R. Wilson ${ }^{3,4}$ and Xiaogong $\mathrm{Hu}^{1}$ \\ 1 Shanghai Astronomical Observatory, Chinese Academy of Sciences, Shanghai 200030, China; hxg@shao.ac.cn \\ 2 University of Chinese Academy of Sciences, Beijing 100049, China \\ 3 Center for Space Research, University of Texas at Austin, Austin, TX 78759, USA; chen@csr.utexas.edu (J.C.); \\ crwilson@jsg.utexas.edu (C.R.W.) \\ 4 Department of Geological Sciences, Jackson School of Geosciences, University of Texas at Austin, Austin, \\ TX 78712, USA \\ * Correspondence: ni.sheng.nan@163.com; Tel.: +86-150-2164-6021
}

Academic Editors: Qiusheng Wu, Charles Lane, Melanie Vanderhoof, Chunqiao Song, Prashant K. Srivastava and Richard Gloaguen

Received: 8 July 2017; Accepted: 9 August 2017; Published: 14 August 2017

\begin{abstract}
Satellite gravity data from the Gravity Recovery and Climate Experiment (GRACE) provides a quantitative measure of terrestrial water storage (TWS) change at different temporal and spatial scales. In this study, we investigate the ability of GRACE to quantitatively monitor long-term hydrological characteristics over the Lake Volta region. Principal component analysis (PCA) is employed to study temporal and spatial variability of long-term TWS changes. Long-term Lake Volta water storage change appears to be the dominant long-term TWS change signal in the Volta basin. GRACE-derived TWS changes and precipitation variations compiled by the Global Precipitation Climatology Centre (GPCC) are related both temporally and spatially, but spatial leakage attenuates the magnitude of GRACE estimates, especially at small regional scales. Using constrained forward modeling, we successfully remove leakage error in GRACE estimates. After this leakage correction, GRACE-derived Lake Volta water storage changes agree remarkably well with independent estimates from satellite altimetry at interannual and longer time scales. This demonstrates the value of GRACE estimates to monitor and quantify water storage changes in lakes, especially in relatively small regions with complicated topography.
\end{abstract}

Keywords: GRACE; Lake Volta; water storage changes; precipitation; leakage error; forward modeling

\section{Introduction}

Terrestrial water storage (TWS) plays a key role in global and regional water cycle, and represents the sum of all water stored above and below Earth's surface, including water in lakes, rivers, man-made reservoirs, wetlands, soil and groundwater reservoirs. TWS is continually exchanged with the atmosphere and oceans through vertical and horizontal fluxes (precipitation, evapotranspiration, surface runoff and underground discharge) [1]. Lake storage is an important TWS component, providing moisture to the atmosphere through evaporation, serving as a climate modulator by absorbing and releasing heat [2], and providing water for agricultural irrigation, domestic and industrial consumption, and hydropower generation. Lake Volta (see Figure 1) is the world's largest man-made lake with a surface area of $\sim 8500 \mathrm{~km}^{2}$, formed by the construction of the Akosombo Dam in 1965. Located completely within Ghana, Lake Volta collects discharge from the numerous rain-fed tributaries within the Volta River basin (VRB), supplies hydroelectric power to Ghana and neighboring 
countries, and is a source of water for irrigation within the basin. However, the water storage in this lake is highly vulnerable to the spatial and temporal variability of rainfall and climate over the VRB.

The VRB extends over at least four climatic regions, from lowland rainforest in the south, to the Sahel-Sudan desert in the north [3]. Climatic patterns in the basin are strongly influenced by the movement of the Inter-Tropical Convergence Zone (ITCZ), which generates unimodal and bimodal rainy seasons $[3,4]$. The north has only one wet season, peaking in September. In the south, there are two rainy seasons with peaks in June-July and September-October. The harmattan climate period (typically from December to February), is characterized by a dry and dusty northeasterly trade wind originating in the Sahara. In January or early February, Lake Volta lies entirely within harmattan-affected areas, with dry, warm days and cool nights [5]. The moist monsoon from June to September and the cold harmattan winds in the dry season cause large seasonal fluctuations of water storage (or water level) in Lake Volta. In addition, the difference in seasonal minimum and maximum levels per year is relatively large, varying between $1.5 \mathrm{~m}$ in 1972 and $7.8 \mathrm{~m}$ in 1989 [5]. Extremely low water level could greatly reduce the generation of hydroelectric power by the dam, and also influence the agriculture in the VRB. Therefore, accurate quantification of long-term water storage changes in Lake Volta (and also in the Volta basin in general) is important for water resources management and agriculture development of VRB.

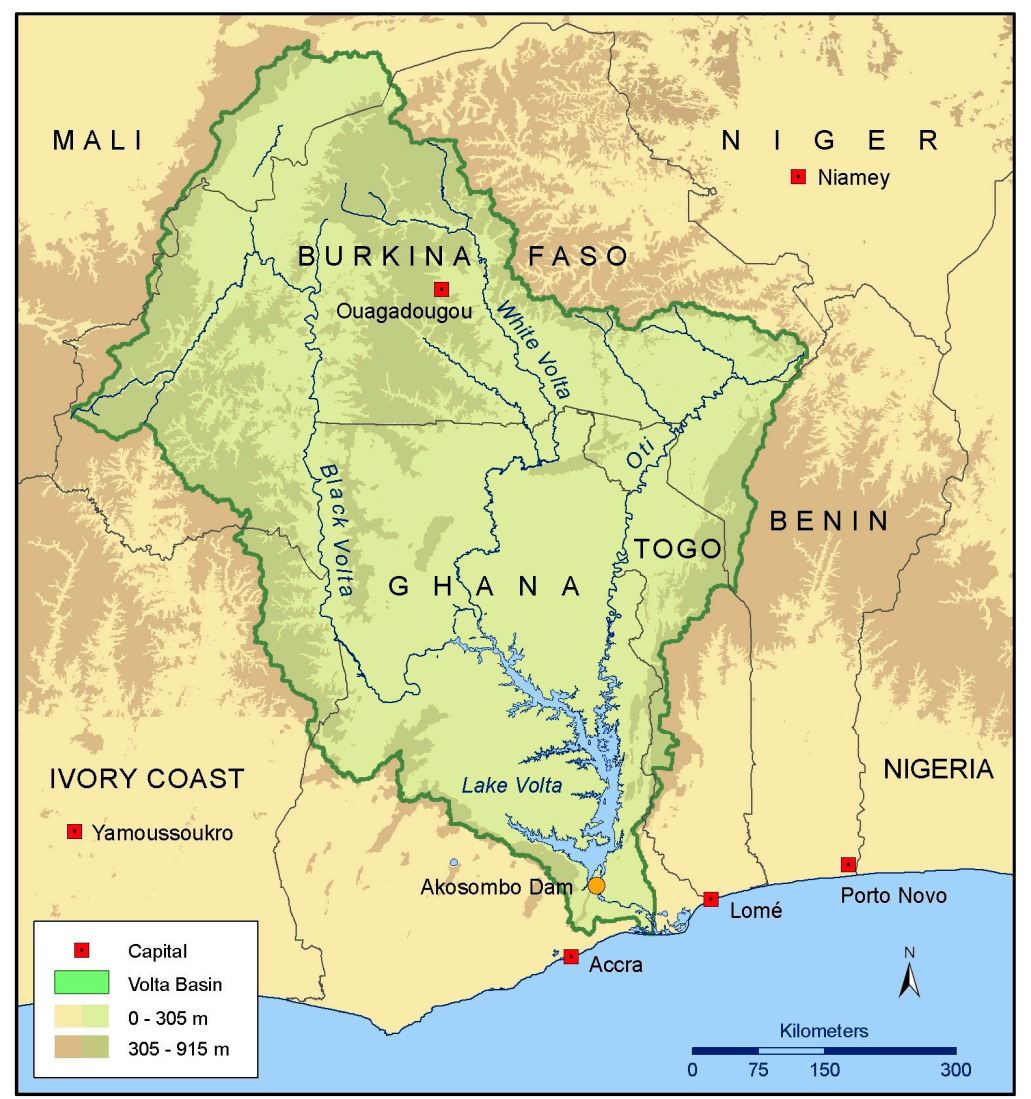

Figure 1. The map of Volta River basin in West Africa. Original map adapted from http:/ / www.zef. de/publ_maps.html.

Accurate estimation of lake water storage variation has been difficult due to lack of adequate in situ measurements on large regional scales. Traditionally, lake water level has been monitored by in situ hydrographic stations, but such data can be intermittently available, or completely inaccessible due to economic or political conditions. As a result, satellite altimetry has become a widely used tool for monitoring water level changes in large lakes, with improved data accuracy 
and calibration algorithms [6]. However, quantification of lake storage change relies on not only accurate measurements of lake levels change, but also good knowledge of the surrounding topography and bathymetry, which are often poorly known. Satellite altimetry and imagery could be used to compute the lake volume variations, but large uncertainty is expected in the small lakes with complicated topography.

Since its launch in March 2002, the Gravity Recovery and Climate Experiment (GRACE) mission [7] has provided global measurements of monthly gravity change, which can be used to estimate TWS change, including the lake storage component. With improved background geophysical models and data processing techniques [8], GRACE RL05 gravity fields show significantly improved quality and spatial resolution. These improvements, plus the extended record of the GRACE time series (over 15 years), have enabled applications to a much wider range of problems, extending to interannual and longer-term time scales.

GRACE estimates have been used to study long-term TWS changes at both global and regional scales [9-14]. For example, Humphrey et al. [12] investigated the relative importance of linear trend and nonlinear interannual variability in long-term TWS changes throughout the world. Awange et al. [9] found out that a catchment area of $4 \times 4^{\circ}$ including Lake Naivasha in East Africa lost water at a rate of $\sim 1.4 \mathrm{~cm} /$ year for the period of 2002-2010. Ahmed et al. [11] and Moore and Williams [13] found that large sectors of Africa are undergoing significant TWS variations ( $+44 \mathrm{~mm} /$ year to $-15 \mathrm{~mm} /$ year) due to natural and anthropogenic causes.

Recently, a few studies (e.g., [11,15]) have noted evidence of increasing TWS over the VRB, especially around Lake Volta. Ahmed et al. [11] and Moore and Williams [13] have attributed this to the impoundment of water by Akosombo Dam. Ndehedehe et al. [16] examined space-time characteristics of droughts over the VRB using GRACE data and multiple drought indices. In addition, studies of VRB water balance have been undertaken using a variety of models and data (e.g., [17-19]). These studies mainly focus on TWS changes in the VRB, but potential of GRACE gravity measurements to monitor and quantify long-term water storage changes in Lake Volta has not been specifically discussed.

In this study, we investigate long-term TWS variability in the VRB, with a focus on Lake Volta, using GRACE RL05 solutions and satellite altimetry lake level measurements. We use principal component analysis (PCA) method [20] to analyze space-time patterns of TWS changes with a focus on understanding long-term variability. We examine the possible connections between GRACE TWS estimates and precipitation variations from the Global Precipitation Climatology Centre (GPCC). The size of Lake Volta is well below the typical spatial resolutions $\left(\sim 300 \mathrm{~km}\right.$ or $\sim 100,000 \mathrm{~km}^{2}$ in area) of GRACE gravity solutions, making it nearly impossible to use regular GRACE solutions to quantify the water storage change of Lake Volta. To overcome the limitation, we apply the constrained forward modeling method [21,22] to remove GRACE leakage error, and restore the true magnitude of the signal. After this leakage correction, the magnitude of the signal is in good agreement with satellite altimetry observations.

\section{Data Processing}

\subsection{GRACE Data}

We use GRACE RL05 monthly gravity fields from the Center for Space Research (CSR), University of Texas at Austin, in the form of fully normalized spherical harmonics (SH) Stokes coefficients up to degree and order 60 [8]. GRACE $C_{20}$ coefficients have been replaced by satellite laser ranging (SLR) solutions provided by Cheng and Tapley [23]. Degree-1 terms (representing geocenter motion) are absent in GRACE gravity solutions, and reliable long-term geocenter variations derived from geodetic observations are not available at present [24]. Here we neglect the effects of degree-1 terms on small regional TWS estimates. Atmospheric, oceanic and tidal effects have been removed using numerical models during GRACE data processing [8]. Therefore, GRACE estimates of mass variations over land 
primarily reflect changes in TWS (including snow/ice), plus other unmodeled signals such as those related to postglacial rebound (PGR) or tectonics.

The 149 approximately monthly gravity solutions cover the period from April 2002 to December 2015 (with a few missing months). For each monthly solution, a long-term mean over the 14-year period has been removed from the monthly SH coefficients. GRACE SH coefficients are contaminated by both systematic and random errors, including longitudinal stripes associated with the GRACE polar orbit, aliases of tide model errors, and some other errors [25]. We use the decorrelation filter P4M6 [26,27] to suppress longitudinal stripe noise, and $300 \mathrm{~km}$ Gaussian smoothing [28] to further suppress residual errors in high degree $\mathrm{SH}$ coefficients.

Based on the equations of Wahr et al. [29] we compute monthly mass change fields (in the form of equivalent water height) on global $1 \times 1^{\circ}$ grids, using the filtered SH coefficients. GRACE TWS change time series of the VRB are then calculated from the monthly mass fields using a $1 \times 1^{\circ}$ basin mask. Considering the small area of Lake Volta, we compute mass change fields over the lake region on a $0.1 \times 0.1^{\circ}$ grid, and then obtain the Lake Volta mass change time series using a $0.1 \times 0.1^{\circ}$ lake mask . The major challenge in estimating TWS changes with GRACE gravity solutions is spatial leakage error introduced by both the limited range of SH coefficients (degree and order 60) and the applied Gaussian smoothing [22]. Therefore, we employ a forward modeling method to remove the leakage error, and compare the resulting GRACE Lake Volta water storage changes with the satellite altimetry observations, as discussed in details in Section 3.

\subsection{Satellite Altimetry}

Since the beginning of the 1990s, satellite radar altimetry has become a successful technique for monitoring height variations of continental surface water. The surface water level is measured within a terrestrial reference frame with repeatability varying from 10 to 35 days (depending on the orbit cycle of the satellite). Using multi-satellite observations, the LEGOS (Laboratoire d'Etudes en Géophysique et Océanographie Spatiale) has developed a web database (Hydroweb: http:/ /hydroweb.theia-land.fr) containing time series of water levels for large rivers, lakes and wetlands on a global scale [30]. In this study, the water levels of Lake Volta are based on the merged Topex/Poseidon, Jason-2, and Envisat observations. The surface of reference is GGM02C, a high resolution global gravity model developed to degree and order 200 [31]. All classical corrections (polar and solid Earth tides, ionospheric and tropospheric delay, and altimeter biases) have been applied to these altimetry data.

\subsection{Precipitation Data}

GPCC was established in 1989 at the Deutscher Wetterdienst (DWD, German Weather Service) on request of the World Meteorological Organization (WMO) as the in situ component of the Global Precipitation Climatology Project (GPCP) [32,33]. GPCC provides gridded precipitation products (http:/ /gpcc.dwd.de) at various temporal and spatial resolutions by analyzing the database from up to 67,000 gauge stations around the world. Here we use Monitoring Product Version 5.0 with spatial resolution of $1 \times 1^{\circ}$ from April 2002 to December 2015. Neither a decorrelation filter nor Gaussian smoothing is applied to the GPCC dataset.

\section{Results}

\subsection{Water Storage Changes from GRACE}

Figure 2 shows TWS changes from GRACE over the VRB. The peak-to-peak GRACE TWS variations are up to $\sim 30 \mathrm{~cm}$. Maximum TWS change tends to occur in September and the minimum in April. GRACE TWS estimates indicate a mass increase from 2007 to 2010 and a decline from 2011 to 2015. The declining amplitude of the TWS changes in 2011 may be partly attributed to the opening of spillways in the Akosombo dam, due to heavy rainfall caused by a La Niña event in 2010 [34]. 


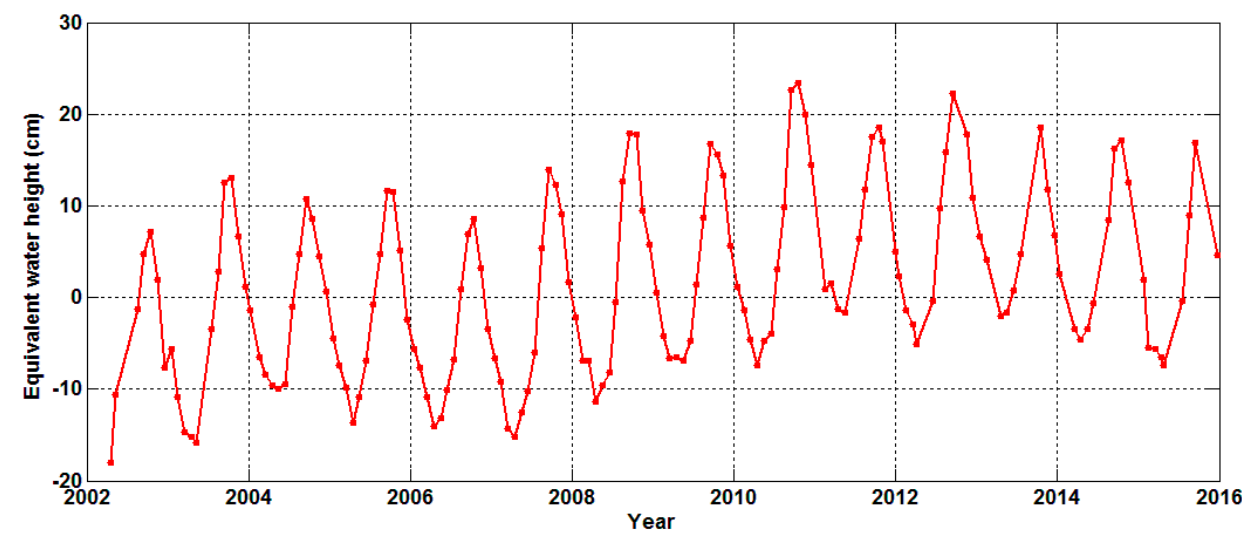

Figure 2. Total water storage changes from the Gravity Recovery and Climate Experiment (GRACE) over the Volta River basin as outlined in Figure 1.

We use least squares to estimate annual and semi-annual terms, and subtract these to obtain non-seasonal TWS changes in the VRB. Spatial and temporal patterns of long-term (i.e., interannual and longer period) TWS changes are evaluated using a PCA method to identify significant modes of variability in GRACE TWS changes in the VRB. Figure 3 shows patterns of the first two modes. Each PCA mode is a combination of temporal and spatial patterns, which should be interpreted together (i.e., the dimensionless temporal evolution should be multiplied by the corresponding spatial pattern in order to obtain the actual values). The percentages of the total variance explained by the first two principal components are $30.9 \%$ and $20.7 \%$, respectively. In the first PCA mode, the largest long-term TWS changes are found over Lake Volta, while in the northern VRB, changes are relatively small. A large proportion of long-term TWS changes over the VRB could be attributed to water storage variations within Lake Volta. In addition, the spatial pattern of long-term TWS changes over the VRB is consistent with its climatic pattern (rainforest in the south and Sahel-Sudan in the north). In the second PCA mode, there is no significant long-term change in the temporal pattern (Figure 3d), only some irregular fluctuations near zero.

(a) EOF1-GRACE $30.9 \%$

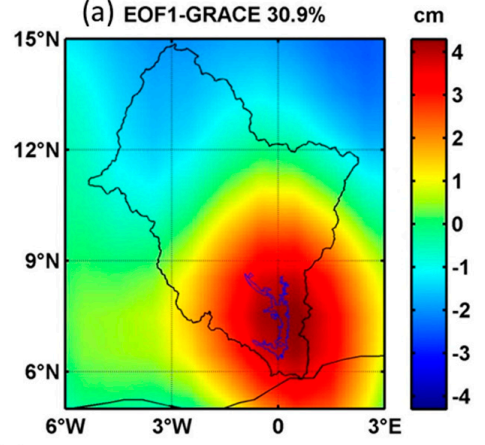

(c)

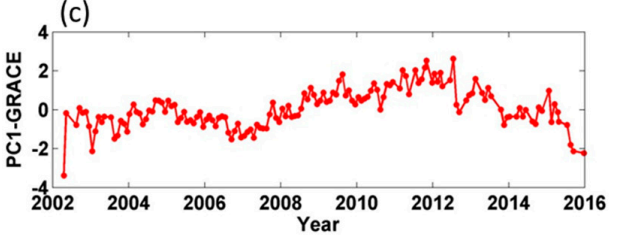

(b) EOF2-GRACE $20.7 \%$

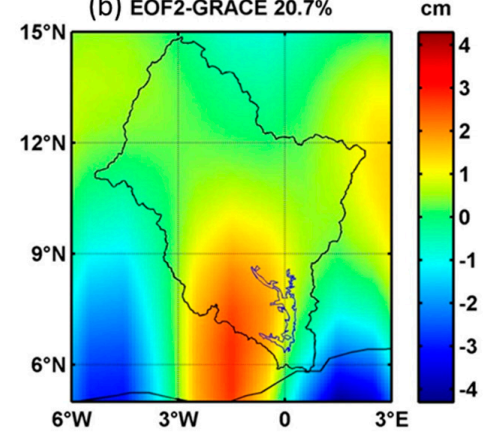

(d)

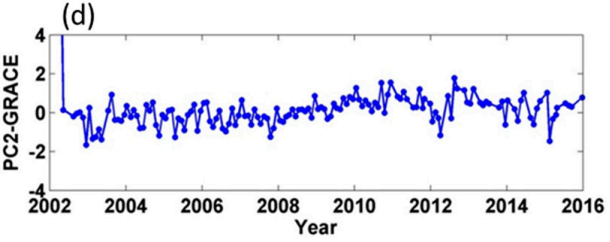

Figure 3. Principal component analysis (PCA)-derived spatial and temporal patterns of terrestrial water storage (TWS) variability (with annual and semiannual signals removed) over the Volta River basin. $(\mathbf{a}, \mathbf{b})$ are spatial patterns of the first two modes derived from PCA; $(\mathbf{c}, \mathbf{d})$ are corresponding temporal patterns. The percentages of the total variance explained by the first two principal components are $30.9 \%$ and $20.7 \%$, respectively. 
Figure 4 shows GRACE water storage changes and satellite altimetry water level changes for Lake Volta. The extreme drought years of 2006/2007 and 2015 in the VRB are apparent in the GRACE results (Figures $3 \mathrm{c}$ and $4 \mathrm{a})$. We find significant increasing $(\sim 4.5 \mathrm{~cm} /$ year) and declining $(\sim-3.4 \mathrm{~cm} /$ year $)$ trends in Lake Volta storage change during the periods of 2007-2010 and 2011-2015. The linear rates ( $\sim 2.30 \mathrm{~m}$ /year and $\sim-2.24 \mathrm{~m} /$ year) of water level change from satellite altimetry are much larger than GRACE results (Figure 4). However, GRACE estimates represent the sum of changes in all reservoirs, including surface water, soil moisture and groundwater, and are subject to significant attenuation effect due to leakage error [22]. Lake storage change is only part of the total TWS variations. Despite large difference in magnitude, in Figure $4 c$, the overall trends of long-term signals from GRACE and satellite altimetry are generally in agreement (correlation coefficient is $\sim 0.89$ ), showing that GRACE is sensitive to Lake Volta storage change, and indicating that GRACE should be useful for monitoring long-term TWS variations at relatively small regional scales, as exemplified by Lake Volta, if attenuation effect or leakage error can be removed.

(a) GRACE

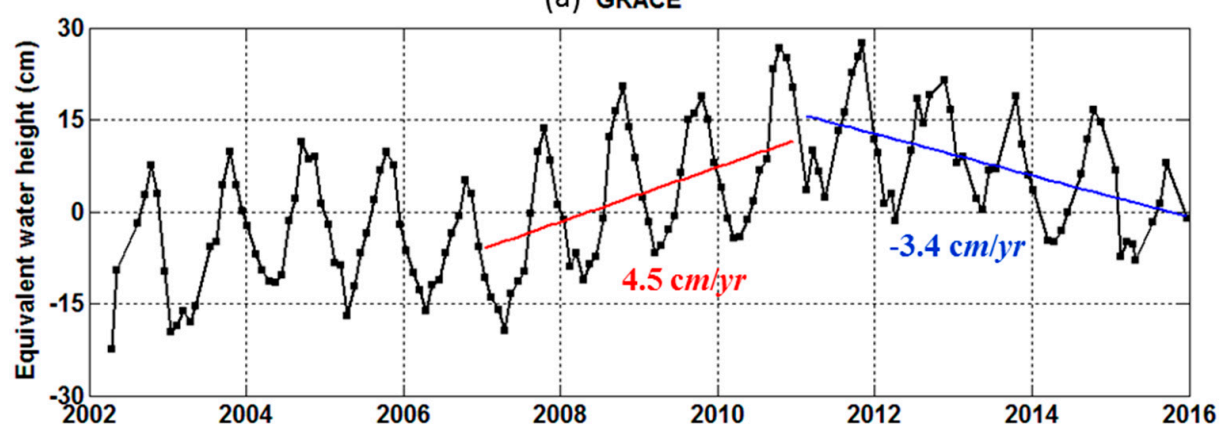

(b) Altimetry

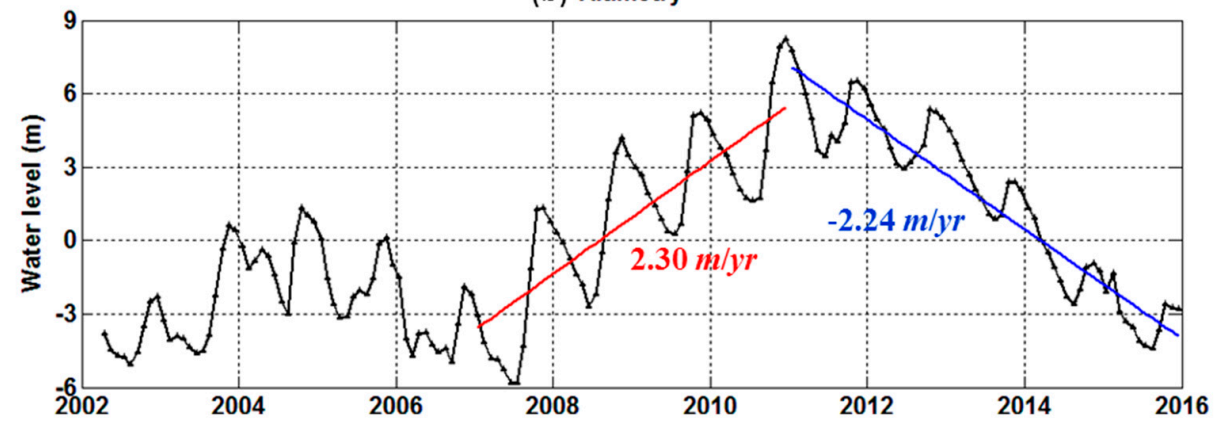

(c) Comparison

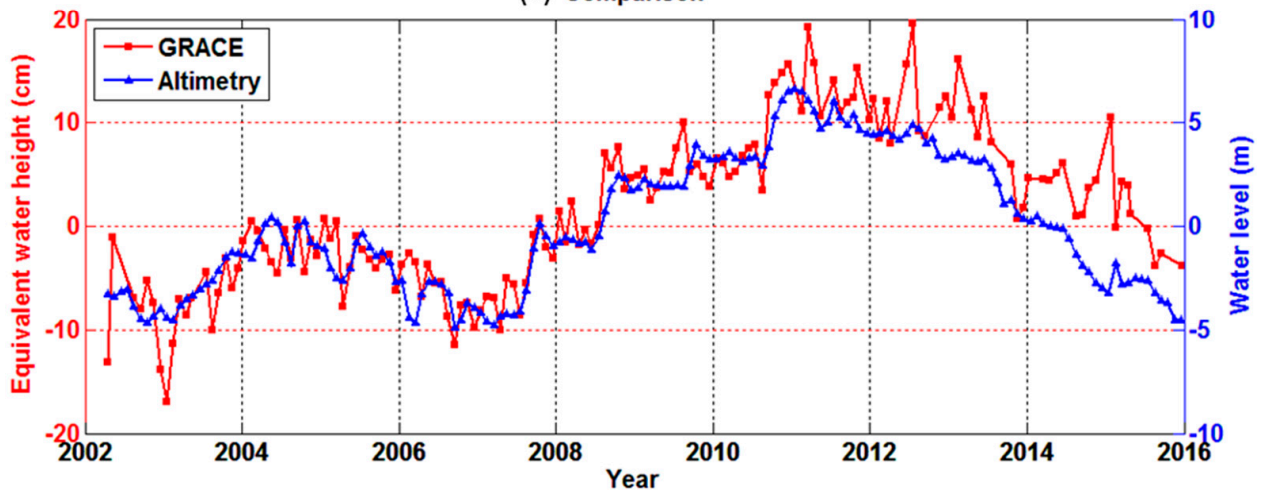

Figure 4. GRACE water storage changes and satellite altimetry water level changes for Lake Volta. Both time series in (a,b) have an increasing (2007-2010) and declining (2011-2015) rate; (c) is the comparison between GRACE and satellite altimetry at long-term time scale. We have removed the annual and semi-annual signals using least squares fitting. Please notice the different $y$-axis scales used in (c). 


\subsection{Connection with Precipitation}

In a basin-scale region, TWS changes ( $\Delta$ TWS) over a time period $(\Delta t)$ reflect the balance of precipitation (P), evapotranspiration (E) and runoff (inflow $R_{\text {in }}$ and outflow $\mathrm{R}_{\text {out }}$ ) as,

$$
\frac{\Delta \mathrm{TWS}}{\Delta \mathrm{t}}=\mathrm{P}-\mathrm{E}+\mathrm{R}_{\text {in }}-\mathrm{R}_{\text {out }}
$$

If the sum of these fluxes $\left(\mathrm{P}, \mathrm{E}, \mathrm{R}_{\text {in }}\right.$ and $\left.\mathrm{R}_{\text {out }}\right)$ contains a constant signal of the form $\beta$, it would translate into a linear signal in water storage ( $c$ is a constant):

$$
\mathrm{TWS}_{\text {linear }}=\beta t+c
$$

Conversely, a linear trend in water storage implies a constant signal in the combination of the four hydrological fluxes.

Figure 5 shows GPCC monthly precipitation over the VRB after removing the climatologic average. The red curve represents the long-term precipitation anomaly smoothed with a Butterworth low-pass (below 0.5 cpy) filter. Precipitation anomaly trends for the periods of 2002-2004, 2005-2007, 2007-2010 and 2011-2015 are positive, negative, positive and negative, respectively, and are evident in increasing and declining TWS variations in Figures $3 \mathrm{c}$ and 4, as predicted by Equation (2) in the presence of alternately wet and dry conditions over the VRB. Two La Niña events during the periods of 2007-2008 and 2010-2011 might lead to the large precipitation anomalies and extreme wet conditions in 2007 and 2010 over the basin. Therefore, the temporal evolutions of precipitation anomalies could suggest the possible influence of El Niño Southern Oscillation (ENSO) on the wet/dry conditions of Volta basin. However, ENSO is not the only climate factor influencing the precipitation anomalies. Other large-scale ocean-atmosphere oscillations such as Indian Ocean dipole (IOD) and Pacific Decadal Oscillation (PDO) might also be connected with the temporal evolutions of precipitation in this basin [16].

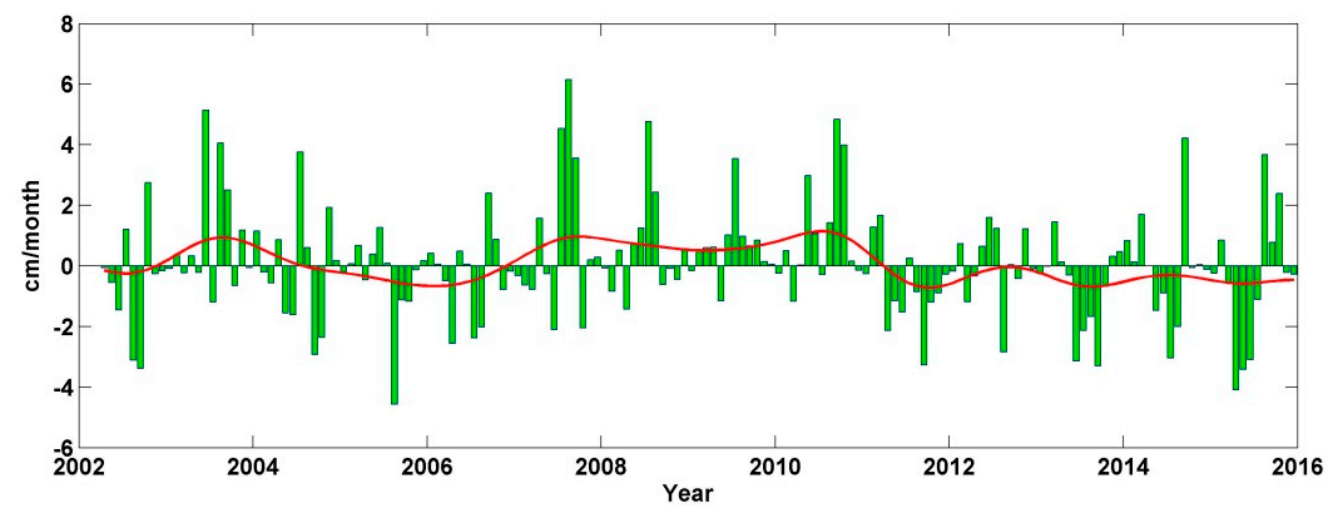

Figure 5. Global Precipitation Climatology Centre (GPCC) monthly precipitation over the Volta River basin with the climatologic average removed. The climatological precipitation is calculated by averaging the monthly precipitation of all the same months over a certain period (e.g., the 20-year period from January 1996 to December 2015). The red line is the nonseasonal precipitation anomaly smoothed with a Butterworth low-pass (below 0.5 cpy) filter.

To further investigate possible connections between TWS changes and precipitation, we compare long-term TWS change rates and mean precipitation anomalies over the VRB during the periods of 2007-2010 (Figure 6a,b) and 2011-2015 (Figure 6c,d). Rainfall varies greatly across the entire basin, and spatial patterns of GPCC precipitation anomalies and GRACE TWS change rates generally agree well. The correlation coefficients between precipitation anomalies and TWS change rates for periods 2007-2010 and 2011-2015 are $~ 0.82$ and $~ 0.83$, respectively. Precipitation in the lower VRB shows positive/negative anomalies for 2007-2010/2011-2015, consistent with increasing/declining TWS 
changes around Lake Volta. This indicates that positive/negative rates of TWS change are due to above/below-normal precipitation variations.

(a) GRACE $300 \mathrm{~km}$

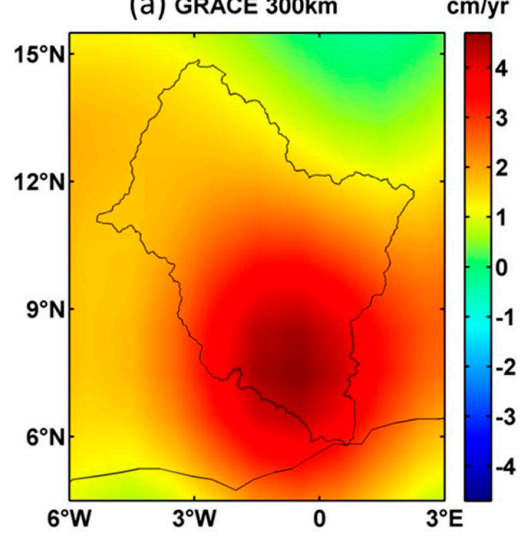

(c) GRACE $300 \mathrm{~km}$

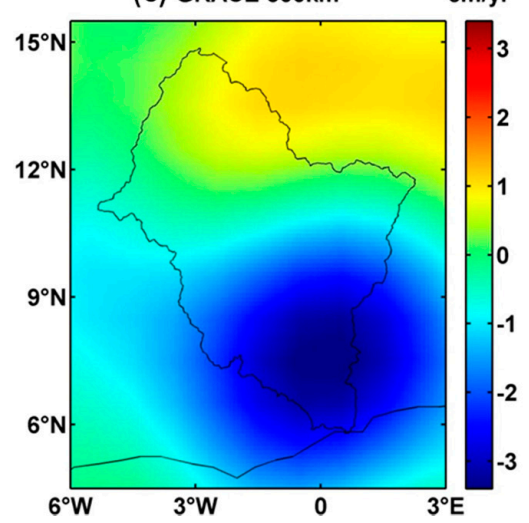

(b) GPCC 0km

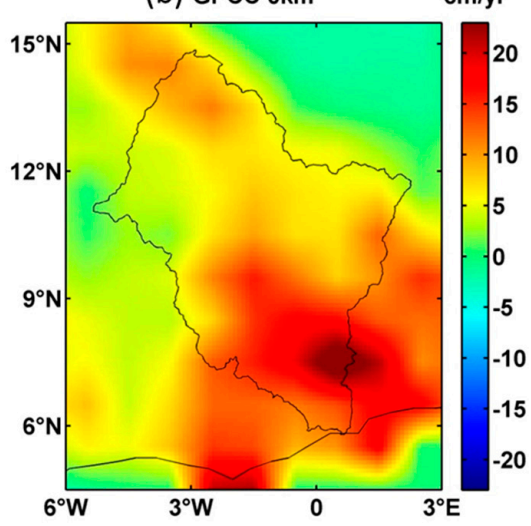

(d) GPCC 0km

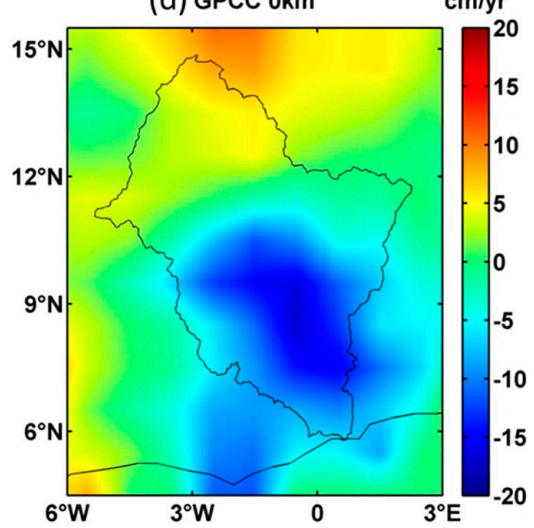

Figure 6. GRACE TWS long-term change rates and GPCC mean precipitation anomalies over the Volta River basin during the periods of 2007-2010 and 2011-2015. (a) is TWS long-term change rates from 2007 to 2010 after P4M6 decorrelation filtering and $300 \mathrm{~km}$ Gaussian smoothing; (b) is mean precipitation anomalies from 2007 to 2010 without any smoothing filter; (c) is TWS long-term change rates from 2011 to 2015 after P4M6 decorrelation filtering and $300 \mathrm{~km}$ Gaussian smoothing; (d) is mean precipitation anomalies from 2011 to 2015 without any smoothing filter. Mean precipitation anomalies are the average values of precipitation with a certain period (e.g., 20 years) climatology removed.

\subsection{Reducing Leakage Errors in GRACE Estimates}

GRACE TWS estimates (Figures 7a and 8a) are subject to spatial leakage error introduced by both a limited range of SH coefficients (degree and order 60) and $300 \mathrm{~km}$ Gaussian smoothing. Leakage effect is associated with both limited spatial resolution and attenuated signal amplitudes (e.g., [35,36]). Forward modeling has been shown to be an effective tool to remove or reduce GRACE leakage error [22]. Here we assume that GRACE long-term mass rates over the Lake Volta region are mainly due to Lake Volta storage changes, and that surrounding regions make a minor contribution. With this assumption, we use constrained forward modeling to find a mass rate that is spatially concentrated within Lake Volta. This is a brief description of the procedure (following Chen et al. [22]):

(1) At each grid point of $0.1 \times 0.1^{\circ}$ over Lake Volta (the red/blue shaded region in Figures $7 \mathrm{~b}$ and $8 \mathrm{~b})$, the initial modeled mass rate is assigned to zero.

(2) We compute the predicted mass rate at each grid point, by representing the $0.1 \times 0.1^{\circ}$ mass model into fully normalized SH coefficients up to degree and order 60 . Then $300 \mathrm{~km}$ Gaussian smoothing is applied and the result is compared with GRACE apparent rate. 
(3) At each grid point, the average difference between GRACE apparent rate (Figures 7a and 8a) and predicted mass rate (Figures 7c and 8c) over Lake Volta is added to the model rate.

(4) After adjusting the model, steps 2-3 are repeated until the residual difference between GRACE apparent rate and predicted mass rate falls below a specified tolerance, or a certain number of iterations is exceeded.

Forward modeling is applied to GRACE rates for the separate periods 2007-2010 and 2011-2015. TWS rates estimated by constrained forward modeling are shown in Figures $7 \mathrm{~b}$ and $8 \mathrm{~b}$, respectively. These are mass variations that yield predicted data (Figures $7 \mathrm{c}$ and $8 \mathrm{c}$ ) that agree well with the GRACE observations (Figures 7a and 8a) in both cases. Before the leakage correction, the increasing and declining TWS rate over Lake Volta is $\sim 4.5 \mathrm{~cm} /$ year and $\sim-3.4 \mathrm{~cm} /$ year, for the two periods, respectively. While after forward modeling, the GRACE rate is $\sim 185.8 \mathrm{~cm} /$ year and $\sim-140.4 \mathrm{~cm} /$ year, respectively, both about 41.3 times of the GRACE observed mass rates prior to leakage correction. The good agreement of signal magnitudes and spatial patterns in Figure $7 a, c$ (or Figure $8 a, c)$ indicates that long-term mass changes around the Lake Volta region are indeed dominantly caused by Lake Volta water storage change. The differences between observed and predicted mass rates over Lake Volta are below $0.5 \mathrm{~cm} /$ year (Figures $7 \mathrm{~d}$ and $8 \mathrm{~d}$ ), far less than $1 \%$ of forward modeled true mass rates $(\sim 185.8 \mathrm{~cm} /$ year and $\sim-140.4 \mathrm{~cm} /$ year for the two periods). Figures 9 and 10 show evolutions of root mean square (RMS) differences between GRACE apparent rates and predicted mass rates as a function of numbers of iterations. In both cases, RMS differences decrease monotonically, and eventually converge to a minimum.
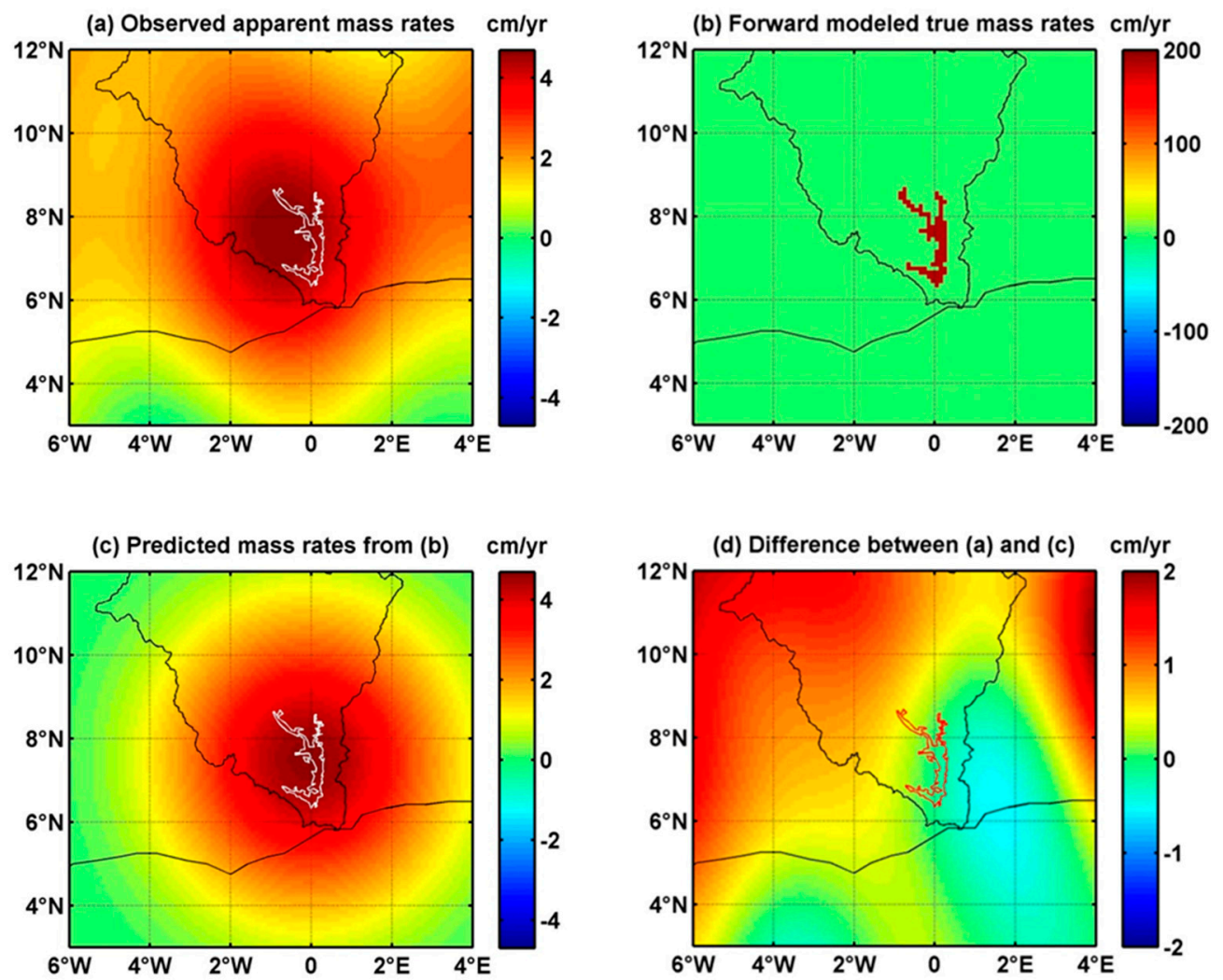

Figure 7. Mass rates (January 2007-December 2010) in $\mathrm{cm} /$ year of equivalent water height. (a) Apparent long-term TWS change rates from GRACE after P4M6 decorrelation filtering and $300 \mathrm{~km}$ Gaussian smoothing; (b) Restored "true" long-term TWS change rates from constrained forward modeling after 300 iterations; (c) Predicted TWS change rates from model rates of (b); (d) Difference between observed and modeled apparent mass rates (i.e., $(\mathbf{a}-\mathbf{c})$ ). Please notice the different color scale used in the four panels. 
(a) Observed apparent mass rates

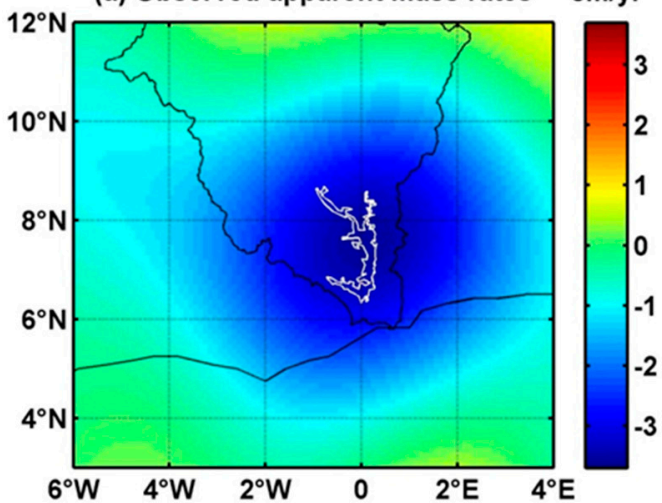

(c) Predicted mass rates from (b)

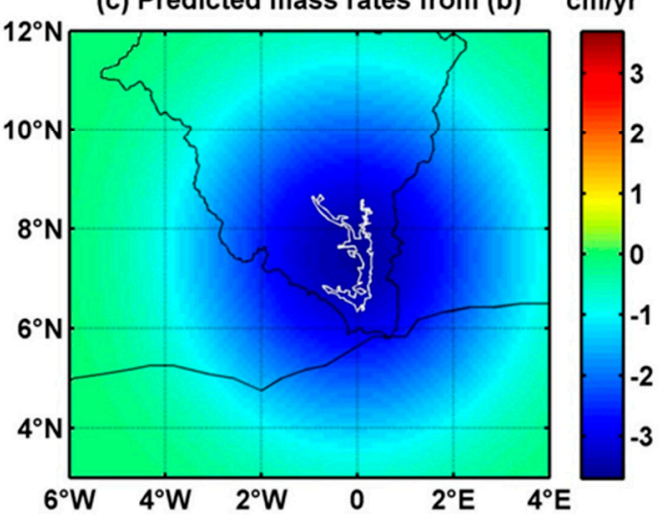

(b) Forward modeled true mass rates $\mathrm{cm} / \mathrm{yr}$

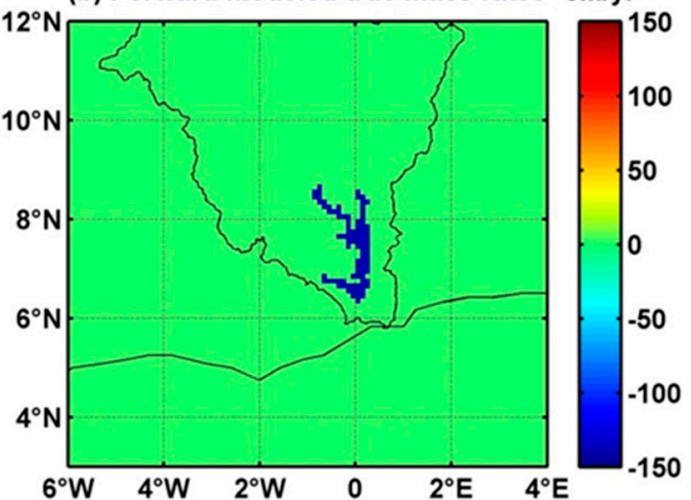

(d) Difference between (a) and (c) $\mathrm{cm} / \mathrm{yr}$

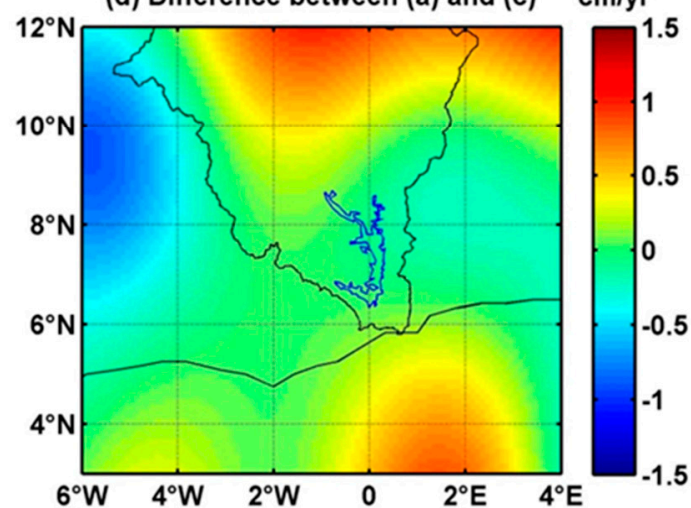

Figure 8. Mass rates (January 2011-December 2015) in $\mathrm{cm} /$ year of equivalent water height. (a) Apparent long-term TWS change rates from GRACE after P4M6 decorrelation filtering and $300 \mathrm{~km}$ Gaussian smoothing; (b) Restored "true" long-term TWS change rates from constrained forward modeling after 200 iterations; (c) Predicted TWS change rates from model rates of (b); (d) Difference between observed and modeled apparent mass rates (i.e., $(\mathbf{a}-\mathbf{c})$ ). Please notice the different color scale used in the four panels.

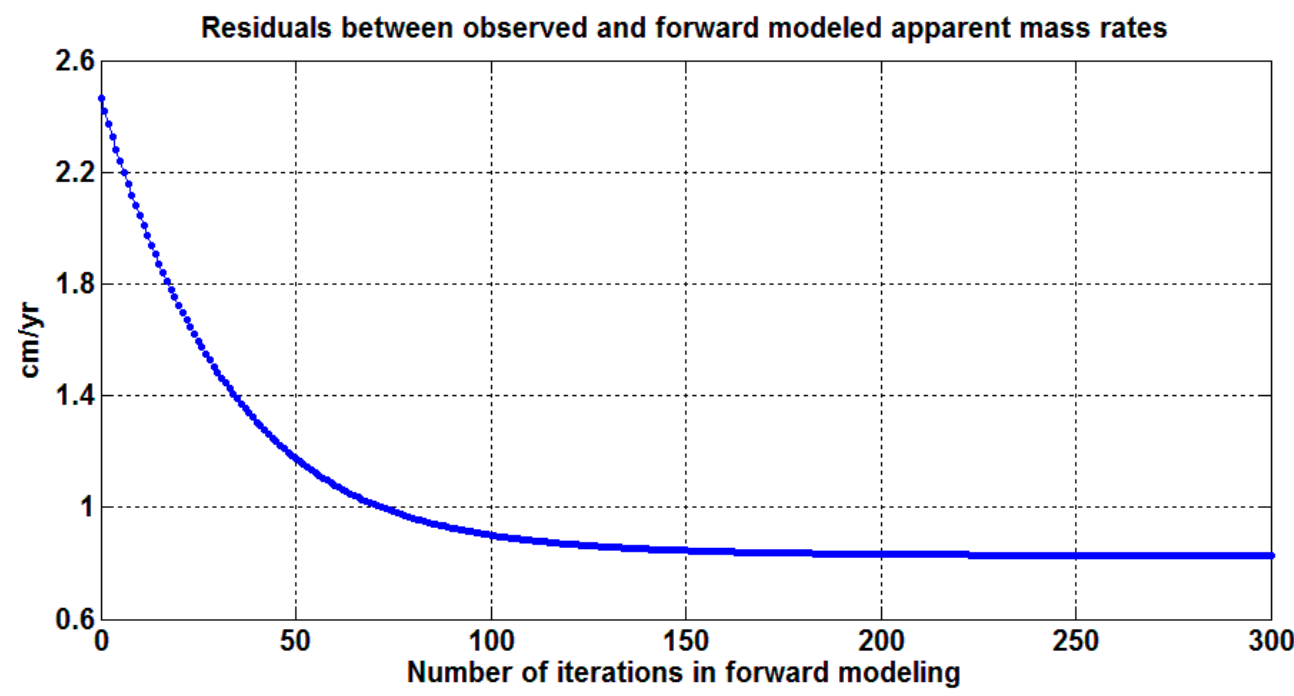

Figure 9. Residuals between observed and apparent mass rates in constrained forward modeling. The residual is computed as the root mean square (RMS) value of difference between observed and modeled data at each grid point over the entire rectangle region shown in Figure 7. 


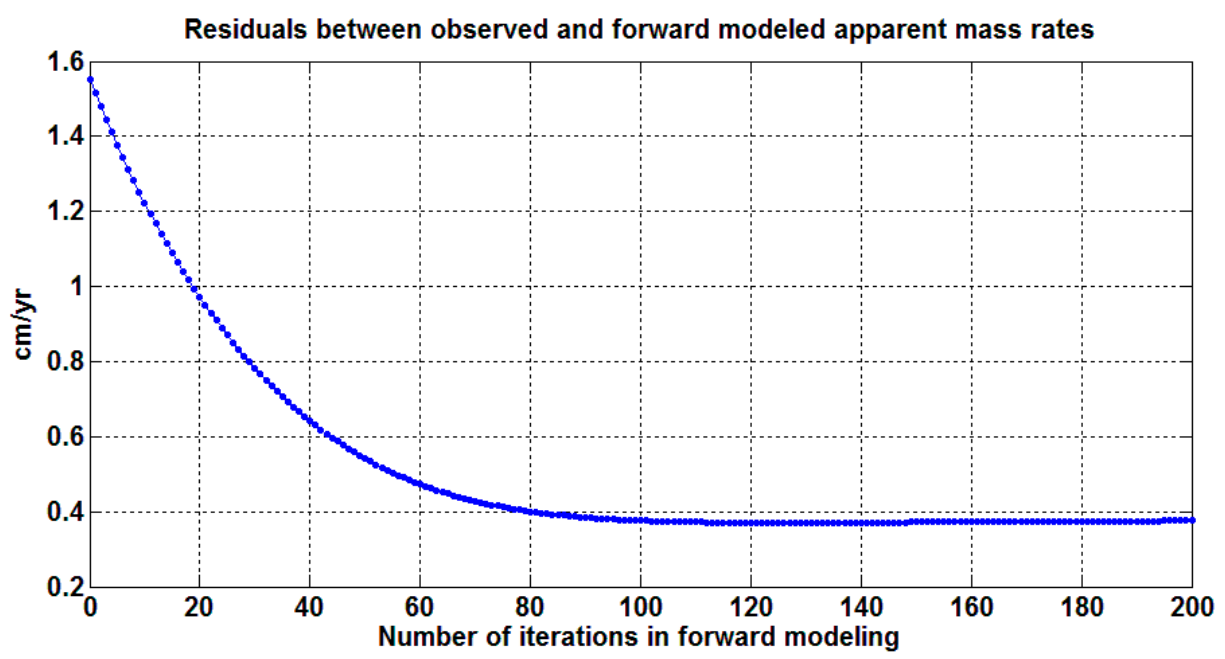

Figure 10. Residuals between observed and apparent mass rates in Figure 8.

Using the forward model estimated scale factor ( 41.3), we recalibrate the GRACE long-term mass changes (in the form of equivalent water height) of Lake Volta, by multiplying scale factor to the GRACE time series (red curve in Figure 4c). The scaled GRACE time series is then used to obtain a GRACE estimate of Lake Volta volume changes (units of $\mathrm{km}^{3}$ ), by multiplying GRACE equivalent water height by the area of the lake mask. The area of the constructed lake mask may be slightly different from the true lake area, but this will not significantly affect GRACE-derived lake volume change, as for small regional mass changes (as in Lake Volta), the forward modeled results are only sensitive to the total mass change assigned to the region [22]. Figure 11 shows the comparisons of Lake Volta water storage changes from GRACE estimates (red curve) and satellite altimetry measurements (blue curve), and the correlation coefficient of this two curves is about $\sim 0.89$. The altimetry lake volume change is the product of altimetry water level change (blue curve in Figure 4c) with estimated lake area as discussed below in Section 3.4. It should be noted that the $y$-axis scale in Figure 11 is the same for GRACE and satellite altimetry data.

In forward modeling experiments, the decorrelation filter P4M6 is used to suppress longitudinal stripe noise, but this may also attenuate true signals with similar shapes. While Lake Volta is indeed oriented mainly north-south, its small spatial scale suggests that signal attenuation may be small. To confirm this, forward modeling has been applied without decorrelation filtering of the GRACE data (only $300 \mathrm{~km}$ Gaussian smoothing was applied). The results are superimposed in Figure 11 (green curve) showing that the effect of decorrelation filter is relatively small at longer periods. The correlation coefficient between restored GRACE estimates without decorrelation filtering and satellite altimetry measurements is about $\sim 0.83$.

After leakage error has been removed via constrained forward modeling, both GRACE estimates (with or without decorrelation filtering) agree quite well with satellite altimetry observations at interannual and longer time scales, especially over the period 2002-2010. GRACE estimates without decorrelation filtering show larger high frequency fluctuations, which is the expected temporal behavior of longitudinal stripe noise. Considering the strong fluctuations in the long-term trends of water level variations (maximum is above $\sim 10 \mathrm{~m}$ ) and the good agreement between restored GRACE estimates and satellite altimetry observations, we could conclude that other hydrological reservoirs (e.g., soil moisture and groundwater) might have very minimal effect on the long-term total storage changes in Lake Volta. However, there remain notable long period differences between scaled GRACE signals and altimetry observations over the period 2011-2015. 


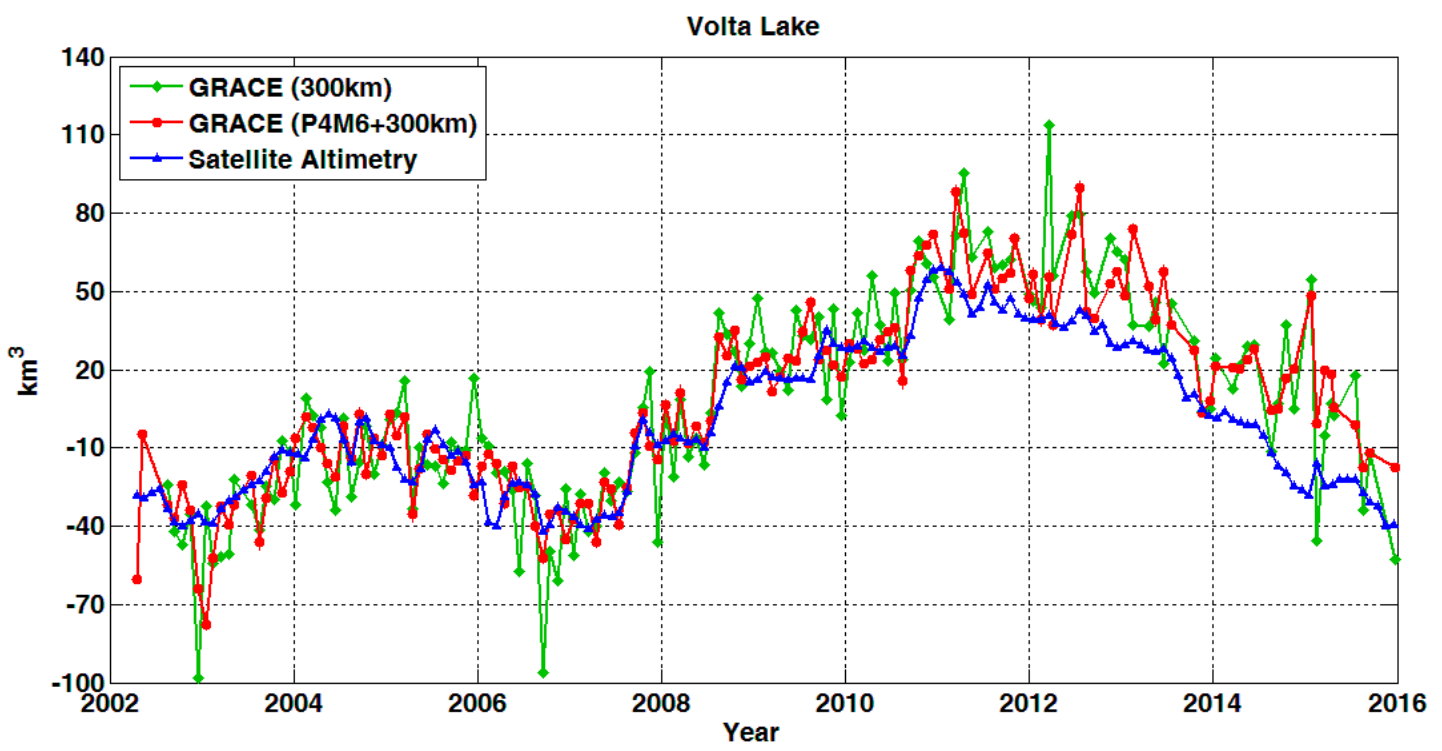

Figure 11. GRACE water storage changes (equivalent water volume) with leakage correction and satellite altimetry water volume changes for Lake Volta. The red curve can be obtained by multiplying the red curve in Figure $4 \mathrm{c}$ with both scale factor $(\sim 41.3)$ and the area of lake mask. The blue curve is the product of altimetry water level change (blue curve in Figure 4c) with estimated lake area. Please notice that the $y$-axis scale in this figure is the same for GRACE and satellite altimetry data.

\subsection{Estimation of Lake Area Change}

While the area of Lake Volta is widely described as $\sim 8500 \mathrm{~km}^{2}$ (e.g., $[19,37]$ ), the lake in fact shrinks during the dry season and swells during the rainy season [38]. Vanderpuye [39] found a linear relationship between the water level and surface area for Lake Volta. Therefore, based on the surface area reported by Ghansah et al. [2], together with the water level derived from satellite altimetry measurements, we obtain the following approximate area-height relationship:

$$
S=6.25 \times 10^{4} h+3875
$$

where $h$ is the height of water level above the surface of reference GGM02C (unit: $\mathrm{km}$ ), and $S$ is the surface area (unit: $\left.\mathrm{km}^{2}\right)$. The volume of Lake Volta $\left(V\right.$, unit: $\left.\mathrm{km}^{3}\right)$ is:

$$
V=\int\left(6.25 \times 10^{4} h+3875\right) d h=3.125 \times 10^{4} h^{2}+3875 h+C_{v}
$$

where $C_{v}$ is a constant of lake volume with respect to the surface of reference. Therefore, using the time series of water level derived from satellite altimetry, we obtain the corresponding altimetry-based water volume changes (Figure 11).

\section{Discussion}

While lake level can be measured both by in situ observations and satellite altimetry, it is challenging to estimate lake volume change, especially in regions with complicated topography as in the case of Lake Volta (Figure 1), where large uncertainty is expected in estimates of lake area. Previous studies (e.g., [38,39]) give substantially different areas (varying by over 50\%) for Lake Volta when using different methods. The particularly large magnitudes (over $10 \mathrm{~m}$ ) of water level fluctuations in Lake Volta make accurate quantification of water storage change more challenging.

GRACE satellite gravity measurements provide a complementary way to monitor water storage changes in the lakes. In Figure 6, the positive/negative rates of GRACE TWS change are consistent with GPCC precipitation anomalies over the same period. This is because positive precipitation anomaly is 
expected to lead to an above-normal inflow into the lake, and vice versa. Due to the large uncertainty of long-term TWS change in hydrological models, in the present study we only rely on GRACE and satellite altimetry data to estimate long-term water storage changes of Lake Volta.

However, GRACE TWS spatial variations are subject to leakage error and related amplitude bias. This is a particular problem when studying Lake Volta storage changes due to its small spatial scale. There is good agreement in temporal variability between GRACE and altimetry observations (Figure 4c) for 2002-2015, but GRACE apparent rates are much smaller due to spatial leakage bias. Forward modeling constrains the location of the mass change to Lake Volta, and provides values that are much more consistent with altimetry at both interannual and long-term time scales, especially for 2002-2010. This shows that GRACE data can be used to monitor changes in such small regions with appropriate handling of the leakage problem, by finding solutions that agree with both GRACE observations and known geography of storage changes. This could effectively improve the virtual spatial resolution of GRACE data, and enable a wider range of applications for GRACE measurements.

The relatively large difference between leakage-corrected GRACE results and altimetry measurements during the later years (2011-2015) may be due to a number of causes: (1) GRACE monitors the sum of all storage changes, including surface water, soil moisture and groundwater, while altimetry measures only lake storage change. In the present analysis, we did not attempt to estimate the separate contribution of soil moisture, part of the GRACE signal, due to lack of reliable estimates from hydrological models; (2) below-normal precipitation for 2011-2015 in the VRB may have led to increased irrigation (causing a decline in lake water level), but GRACE lacks spatial resolution to distinguish the horizontal water movement (i.e., from lake to surrounding lands), leading to underestimation of Lake Volta volume change; (3) lake water volume can be affected by the sediment coming from the surrounding river basin; (4) a possible additional problem is that GRACE measurement quality has declined in the last few years, due to interruptions needed to preserve spacecraft battery life.

The GRACE Follow-On (FO) mission is scheduled for launch in late 2017 or early 2018. In combination, GRACE and GRACE-FO should provide a several decade record of global time-variable gravity measurements that will contribute to understanding of global TWS changes at both several hundred kilometer scales of its nominal resolution, and at smaller scales, where knowledge of source geography can be used to constrain the solutions.

\section{Conclusions}

GRACE RL05 gravity solutions are used to estimate water storage changes over Lake Volta (and surrounding regions) and to examine relationships with precipitation anomalies for the period 2002-2015. We apply the PCA method to identify and analyze long-term TWS spatial patterns and related temporal behaviors. The results show large spatial variability in long-term TWS change in the VRB, and a dominant proportion of long-term TWS change appears to be attributed to water storage change in Lake Volta. After spatial filtering, GRACE measurements show an increasing ( $\sim 4.5 \mathrm{~cm} /$ year $)$ and a declining ( - 3.4 cm/year) TWS change rate over Lake Volta during 2007-2010 and 2011-2015, respectively. These rates are consistent with GPCC precipitation anomalies over the same period. GRACE-derived TWS changes and precipitation variations from GPCC are related both temporally and spatially.

Using constrained forward modeling, we successfully remove leakage error in GRACE estimates. The restored GRACE rate is $\sim 185.8 \mathrm{~cm} /$ year and $\sim-140.4 \mathrm{~cm} /$ year, respectively, both about 41.3 times of the GRACE observed mass rates prior to leakage correction. After this leakage correction, GRACE-derived Lake Volta water storage changes agree remarkably well with independent estimates from satellite altimetry at interannual and longer time scales (Figure 11). This demonstrates the value of GRACE estimates to monitor and quantify water storage changes in lakes, especially in relatively small regions with complicated topography. 
Acknowledgments: The authors are grateful to the membership of the Laboratory of Astronomy and Space Technology Applications at the Shanghai Astronomical Observatory, Chinese Academy of Sciences. This study was supported by the joint PhD scholarship from the Chinese Scholarship Council, the Natural Science Foundation of Shanghai (No. 17ZR1435600), the Open Fund of Key Laboratory of Geospace Environment and Geodesy, Ministry of Education, Wuhan University (16-01-05), the National Key Research and Development Program of China (2016YFB0501405), and the Special Program Fund of Shanghai Astronomical Observatory (Y196591009). This work made use of the High Performance Computing Resource in the Core Facility for Advanced Research Computing at the Shanghai Astronomical Observatory, Chinese Academy of Sciences. The altimeter products were produced by Hydroweb and distributed by Theia, with support from CNES and LEGOS.

Author Contributions: Shengnan Ni carried out the research and wrote the manuscript. Jianli Chen contributed to the preparation of the manuscript through review, editing, and comments. Clark R. Wilson helped polish the manuscript and proposed many useful suggestions to improve its quality. All authors contributed to the discussion of the results, as well as the writing of the manuscript.

Conflicts of Interest: The authors declare no conflict of interest.

\section{References}

1. Llovel, W.; Becker, M.; Cazenave, A.; Crétaux, J.-F.; Ramillien, G. Global land water storage change from GRACE over 2002-2009; Inference on sea level. C. R. Geosci. 2010, 342, 179-188. [CrossRef]

2. Ghansah, B.; Asare, Y.M.; Tchao, E.T.; Forkuo, E.K. Mapping the spatial changes in Lake Volta using multitemporal remote sensing approach. Lakes Reserv. Res. Manag. 2016, 21, 206-215. [CrossRef]

3. Rodgers, C.; van de Giesen, N.; Laube, W.; Vlek, P.L.G.; Youkhana, E. The GLOWA Volta project: A framework for water resources decision-making and scientific capacity building in a transnational West African basin. In Integrated Assessment of Water Resources and Global Change: A North-South Analysis; Craswell, E., Bonnell, M., Bossio, D., Demuth, S., Van De Giesen, N., Eds.; Springer: Dordrecht, The Netherlands, 2007; pp. 295-313.

4. Sultan, B.; Baron, C.; Dingkuhn, M.; Sarr, B.; Janicot, S. Agricultural impacts of large-scale variability of the West African monsoon. Agric. For. Meteorol. 2005, 128, 93-110. [CrossRef]

5. Van Zwieten, P.; Béné, C.; Kolding, J.; Brummett, R.; Valbo-Jorgensen, J. Review of Tropical Reservoirs and Their Fisheries: The Cases of Lake Nasser, Lake Volta and Indo-Gangetic Basin reservoir; Food and Agriculture Organization of the United Nations: Rome, Italy, 2011.

6. Crétaux, J.-F.; Abarca-del-Río, R.; Bergé-Nguyen, M.; Arsen, A.; Drolon, V.; Clos, G.; Maisongrande, P. Lake volume monitoring from space. Surv. Geophys. 2016, 37, 269-305. [CrossRef]

7. Tapley, B.D.; Bettadpur, S.; Watkins, M.; Reigber, C. The gravity recovery and climate experiment: Mission overview and early results. Geophys. Res. Lett. 2004, 31. [CrossRef]

8. Bettadpur, S. UTCSR Level-2 Processing Standards Document for Product Release 05; GRACE 327-742; Center for Space Research, The University of Texas at Austin: Austin, TX, USA, 2012.

9. Awange, J.L.; Forootan, E.; Kusche, J.; Kiema, J.; Omondi, P.; Heck, B.; Fleming, K.; Ohanya, S.; Gonçalves, R. Understanding the decline of water storage across the Ramser-Lake Naivasha using satellite-based methods. Adv. Water Res. 2013, 60, 7-23. [CrossRef]

10. Awange, J.L.; Anyah, R.; Agola, N.; Forootan, E.; Omondi, P. Potential impacts of climate and environmental change on the stored water of Lake Victoria Basin and economic implications. Water Resour. Res. 2013, 49, 8160-8173. [CrossRef]

11. Ahmed, M.; Sultan, M.; Wahr, J.; Yan, E. The use of GRACE data to monitor natural and anthropogenic induced variations in water availability across Africa. Earth Sci. Rev. 2014, 136, 289-300. [CrossRef]

12. Humphrey, V.; Gudmundsson, L.; Seneviratne, S.I. Assessing global water storage variability from GRACE: Trends, seasonal cycle, subseasonal anomalies and extremes. Surv. Geophys. 2016, 37, 357-395. [CrossRef] [PubMed]

13. Moore, P.; Williams, S.D.P. Integration of altimetric lake levels and GRACE gravimetry over Africa: Inferences for terrestrial water storage change 2003-2011. Water Resour. Res. 2014, 50, 9696-9720. [CrossRef]

14. Luo, Z.; Yao, C.; Li, Q.; Huang, Z. Terrestrial water storage changes over the pearl river basin from grace and connections with pacific climate variability. Geod. Geodyn. 2016, 7, 171-179. [CrossRef]

15. Ferreira, V.G.; Gong, Z.; Andam-Akorful, S.A. Monitoring mass changes in the Volta River basin using GRACE satellite gravity and TRMM precipitation. Boletim de Ciências Geodésicas 2012, 18, 549-563. [CrossRef]

16. Ndehedehe, C.E.; Awange, J.L.; Corner, R.J.; Kuhn, M.; Okwuashi, O. On the potentials of multiple climate variables in assessing the spatio-temporal characteristics of hydrological droughts over the Volta Basin. Sci. Total Environ. 2016, 557, 819-837. [CrossRef] [PubMed] 
17. Andam-Akorful, S.A.; Ferreira, V.G.; Awange, J.L.; Forootan, E.; He, X.F. Multi-model and multi-sensor estimations of evapotranspiration over the Volta Basin, West Africa. Int. J. Climatol. 2015, 35, 3132-3145. [CrossRef]

18. Ferreira, V.G.; Andam-Akorful, S.A.; He, X.-F.; Xiao, R.-Y. Estimating water storage changes and sink terms in Volta Basin from satellite missions. Water Sci. Eng. 2014, 7, 5-16. [CrossRef]

19. Ferreira, V.G.; Asiah, Z. An Investigation on the Closure of the Water Budget Methods over Volta Basin Using Multi-Satellite Data; Springer: Berlin/Heidelberg, Germnay, 2015; pp. 1-8. [CrossRef]

20. Jolliffe, I. Principal component analysis. In Wiley StatsRef: Statistics Reference Online; John Wiley \& Sons, Ltd.: Hoboken, NJ, USA, 2014.

21. Chen, J.L.; Li, J.; Zhang, Z.Z.; Ni, S.N. Long-term groundwater variations in Northwest India from satellite gravity measurements. Glob. Planet. Chang. 2014, 116, 130-138. [CrossRef]

22. Chen, J.L.; Wilson, C.R.; Li, J.; Zhang, Z. Reducing leakage error in GRACE-observed long-term ice mass change: A case study in West Antarctica. J. Geod. 2015, 89, 925-940. [CrossRef]

23. Cheng, M.K.; Tapley, B.D. Variations in the Earth's oblateness during the past 28 years. J. Geophys. Res. Solid Earth 2004, 109. [CrossRef]

24. Chen, J.L.; Wilson, C.R.; Tapley, B.D. Contribution of ice sheet and mountain glacier melt to recent sea level rise. Nat. Geosci. 2013, 6, 549-552. [CrossRef]

25. Wahr, J.; Swenson, S.; Zlotnicki, V.; Velicogna, I. Time-variable gravity from GRACE: First results. Geophys. Res. Lett. 2004, 31. [CrossRef]

26. Swenson, S.; Wahr, J. Post-processing removal of correlated errors in GRACE data. Geophys. Res. Lett. 2006, 33. [CrossRef]

27. Chen, J.L.; Wilson, C.R.; Tapley, B.D.; Longuevergne, L.; Yang, Z.L.; Scanlon, B.R. Recent La Plata basin drought conditions observed by satellite gravimetry. J. Geophys. Res. Atmos. 2010, 115. [CrossRef]

28. Jekeli, C. Alternative Methods to Smooth the Earth's Gravity Field; Department of Geodetic Science and Surveying, Ohio State University: Columbus, OH, USA, 1981.

29. Wahr, J.; Molenaar, M.; Bryan, F. Time variability of the Earth's gravity field: Hydrological and oceanic effects and their possible detection using GRACE. J. Geophys. Res. Solid Earth 1998, 103, 30205-30229. [CrossRef]

30. Crétaux, J.F.; Jelinski, W.; Calmant, S.; Kouraev, A.; Vuglinski, V.; Bergé-Nguyen, M.; Gennero, M.C.; Nino, F.; Abarca Del Rio, R.; Cazenave, A.; et al. SOLS: A lake database to monitor in the near real time water level and storage variations from remote sensing data. Adv. Space Res. 2011, 47, 1497-1507. [CrossRef]

31. Tapley, B.; Ries, J.; Bettadpur, S.; Chambers, D.; Cheng, M.; Condi, F.; Gunter, B.; Kang, Z.; Nagel, P.; Pastor, R.; et al. GGM02-An improved earth gravity field model from GRACE. J. Geod. 2005, 79, 467-478. [CrossRef]

32. Schneider, U.; Fuchs, T.; Meyer-Christoffer, A.; Rudolf, B. Global Precipitation Analysis Products of the GPCC; Global Precipitation Climatology Centre (GPCC), Deutscher Wetterdienst: Offenbach, Germany, 2008.

33. Schneider, U.; Becker, A.; Finger, P.; Meyer-Christoffer, A.; Ziese, M.; Rudolf, B. GPCC's new land surface precipitation climatology based on quality-controlled in situ data and its role in quantifying the global water cycle. Theor. Appl. Climatol. 2013, 115, 15-40. [CrossRef]

34. Owusu, K.; Waylen, P.R. The changing rainy season climatology of mid-ghana. Theor. Appl. Climatol. 2013, 112, 419-430. [CrossRef]

35. Guo, J.Y.; Duan, X.J.; Shum, C.K. Non-isotropic Gaussian smoothing and leakage reduction for determining mass changes over land and ocean using GRACE data. Geophys. J. Int. 2010, 181, 290-302. [CrossRef]

36. Chen, J.L.; Wilson, C.R.; Famiglietti, J.S.; Rodell, M. Attenuation effect on seasonal basin-scale water storage changes from GRACE time-variable gravity. J. Geod. 2007, 81, 237-245. [CrossRef]

37. Owusu, K.; Waylen, P.; Qiu, Y. Changing rainfall inputs in the Volta basin: Implications for water sharing in Ghana. GeoJournal 2008, 71, 201-210. [CrossRef]

38. Tanaka, M.; Adjadeh, T.A.; Tanaka, S.; Sugimura, T. Water surface area measurement of Lake Volta using SSM/I 37-Ghz polarization difference in rainy season. Adv. Space Res. 2002, 30, 2501-2504. [CrossRef]

39. Vanderpuye, C.J. Synthesis of information on selected African reservoirs-Lake Volta in Ghana. In Status of African Reservoir Fisheries; Kapetsky, J.M., Petr, T., Eds.; FAO: Rome, Italy, 1984; pp. 261-321.

(C) 2017 by the authors. Licensee MDPI, Basel, Switzerland. This article is an open access article distributed under the terms and conditions of the Creative Commons Attribution (CC BY) license (http:/ / creativecommons.org/licenses/by/4.0/). 